\title{
INOVAÇÃO TECNOLÓGICA E PROCESSO DE ADOÇÃO DE PRODUTOS FABRICADOS COM RESÍDUOS PLÁSTICOS PÓS-CONSUMO
}

\author{
Elaine Ferreira ${ }^{1}$ \\ Maria José Barbosa de Souza ${ }^{2}$
}

\begin{abstract}
Resumo: A reutilização de produtos no processo de reciclagem constitui-se em produção mais limpa, considerada uma inovação tecnológica. Com o objetivo de verificar se existe mercado para mangueiras produzidas com resíduos plásticos pós-consumo reciclados, realizou-se uma pesquisa com 133 empresas da Grande Florianópolis/SC, identificando as quantidades consumidas e a disposição destas em adquirir o novo produto. Os resultados revelam que uma quantidade expressiva de resíduo plástico pós-consumo, gerada na região, pode ser encaminhada para a produção de mangueiras e que os consumidores deste produto precisam ser informados sobre os benefícios da utilização de produto fabricado com matéria-prima reciclada.
\end{abstract}

Palavras-chave: Produção mais limpa. Inovação tecnológica. Adoção de novos produtos. Resíduos plásticos pós-consumo.

\section{INTRODUÇÃO}

O crescimento e o desenvolvimento econômico trouxeram grandes benefícios para a sociedade, porém, também ocasionaram alguns efeitos indesejáveis. Em vista disso, a sociedade sentiu a necessidade de adotar um novo conceito para desenvolvimento, o qual dá ênfase à questão da sustentabilidade.

O ser humano interfere no meio ambiente, gerando resíduos através de suas ações, tanto durante o processo industrial como durante o consumo dos produtos provenientes dele. Os lixões e os aterros controlados são, atualmente, as formas mais usuais de destino dos resíduos sólidos urbanos gerados no Brasil. Tendo em vista que tais alternativas não se apresentam como as soluções mais adequadas para o problema, a reciclagem surge como um modo viável de destino dos resíduos sólidos, pois permite o reaproveitamento destes como matéria-prima, reincorporando-os ao processo produtivo e, dessa forma, reduzindo o seu impacto ambiental. Assim, a reciclagem oferece oportunidades econômicas, sociais e ambientais para os países que a adotarem.

A preocupação com a gestão sócio-ambiental dos resíduos urbanos se faz cada vez mais presente nos debates de organismos públicos e organizações da sociedade civil ligadas ao tema. De acordo com a Pesquisa Nacional de Saneamento Básico - PNSB, realizada pelo Instituto Brasileiro de Geografia e Estatística - IBGE (2000), somente 5,2\% dos resíduos gerados no país eram encaminhados para usinas de reciclagem. Milhares de toneladas de materiais recicláveis desaparecem soterrados ou são dispostos a céu aberto nos lixões. O Instituto de Pesquisas Tecnológicas - IPT (1996) conceitua lixão, como o local onde há uma inadequada disposição final de resíduos sólidos,

\footnotetext{
1 UNIVALI, Biguaçu, SC. E-mail: elainefer@uol.com.br

2 UNIVALI, Biguaçu, SC. E-mail: $\underline{\text { mjbsouza@matrix.com.br }}$
} 
caracterizado pela simples descarga destes sobre o solo, sem medidas de proteção ao meio ambiente ou à saúde pública.

A cidade de Florianópolis, capital do estado de Santa Catarina, localizado na região sul do Brasil, tem apresentado um aumento significativo na área total construída de residências multifamiliares, em função do crescimento populacional. De acordo com o Sindicato das Indústrias da Construção Civil - SINDUSCOM (2005), no período de 1999 a 2003, essa área passou de aproximadamente 200.000 para 2.000 .000 de metros quadrados, levando-se em conta os alvarás de construção emitidos.

As mangueiras plásticas, corrugadas e lisas, são utilizadas nas obras civis como condutores elétricos e hidráulicos, por isso muito comercializadas. Normalmente, a matéria-prima para sua fabricação é proveniente de indústrias petroquímicas, porém podem ser produzidas a partir de resíduos plásticos pós-consumo, sem comprometer sua qualidade.

Nesse contexto, o presente trabalho objetiva responder à seguinte questão de pesquisa: a) existe mercado para mangueiras corrugadas e lisas produzidas com resíduos plásticos pós-consumo reciclados?

Para responder a esta questão, realizou-se um estudo na região da Grande Florianópolis, com os seguintes objetivos específicos: a) identificar as empresas que utilizam mangueiras plásticas e as quantidades deste produto consumidas mensalmente; b) verificar se estas empresas estariam dispostas a adquirir o material produzido com resíduo plástico pós-consumo; c) levantar a quantidade de resíduo plástico gerado pelas organizações, que pudesse ser reciclado.

O trabalho encontra-se estruturado da seguinte forma, além desta introdução. Inicialmente apresentam-se dados sobre produção mais limpa, inovação tecnológica e reciclagem, seguidos da metodologia utilizada e dos principais resultados encontrados na pesquisa. Finalmente, faz-se algumas recomendações nas considerações finais.

\section{REVISÃO BIBLIOGRÁFICA}

\subsection{PRODUÇÃO MAIS LIMPA E INOVAÇÃO TECNOLÓGICA}

Um fator importante a ser considerado na produção de bens e serviços é a utilização mais eficiente das matérias primas renováveis e não renováveis, tanto pelas organizações produtoras quanto pelos consumidores. Uma das possíveis abordagens para enfrentar tal desafio é o emprego de tecnologias mais limpas, que incluem práticas de manutenção, otimização de processo, substituição de matéria prima, novas tecnologias e novo projeto de produto. Sua finalidade é prevenir o uso ineficiente de matérias primas e reduzir custos operacionais, de tratamento e de descarte. Essas tecnologias fazem parte do conceito de Produção Mais Limpa, proposto pela United Nations Industrial Development Organization - UNIDO (UNIDO, 2004).

A Produção Mais Limpa é uma inovação tecnológica que gera benefícios econômicos e ambientais para a empresa, já que tem como base a diminuição dos resíduos gerados e 0 desenvolvimento de produtos que causem menor impacto ambiental no final do seu ciclo de vida. Nesse tipo de produção, devem ser observados os seguintes aspectos: a) substituição de matériasprimas não renováveis; b) implementação de melhorias no processo de manufatura, definindo as necessidades de insumos e a viabilidade da reciclagem e reutilização de subprodutos; c) análise das implicações ambientais da embalagem e da forma de distribuição do produto; e d) considerações sobre a reciclagem ou a reutilização do produto ao final de sua vida útil (UNIDO, 2004). 
Segundo Betz (1987), o conceito de inovação, quando relacionado à área de produção, pode ser entendido como a introdução de novos produtos, processos e serviços no mercado. Esse autor entende que a inovação tecnológica ocorre quando se utiliza uma nova tecnologia para implementar a inovação. Por essa razão, pode-se inferir que a produção mais limpa é uma forma de inovação tecnológica.

Para Barbieri (1997), existem quatro formas de uma inovação ser aplicada em uma empresa, quais sejam: a) criação de um novo processo produtivo ou alteração de um existente; b) modificação de um produto existente ou a substituição por outro que cumpra a finalidade principal; c) fabricação de novos produtos, a partir de um processo produtivo comum ou afim; e d) implementação de novas tecnologias na empresa com vistas à fabricação de novos produtos.

A inovação tecnológica está diretamente relacionada com a adoção de uma nova tecnologia. $A$ adoção é definida como a decisão de uma pessoa de se tornar um usuário regular de um processo, de um produto ou de um serviço. As inovações levam tempo para serem disseminadas pelo sistema social. Rogers (1983) conceitua o processo de difusão de inovações como a disseminação de uma nova idéia, a partir de sua fonte de invenção ou criação para seus usuários finais adotantes. A adoção de inovações passa por cinco etapas: conscientização, interesse, avaliação, experimentação e adoção. A empresa que lança um novo produto deve facilitar a passagem do usuário por essas etapas, através de um programa baseado em um modelo de comunicação que leve o potencial usuário a agir em busca do novo produto.

Stoner e Freeman (1982) salientam que as organizações são impactadas por diversas variáveis, dentre elas a tecnológica, caracterizada por aperfeiçoamentos em produtos, processos e materiais. O desenvolvimento da tecnologia determina, em grande parte, quais produtos serão produzidos, qual equipamento será mais adequado ao processo produtivo e como serão administradas as operações. Esses avanços são cada vez mais freqüentes e mais complexos, influenciando de forma definitiva as empresas, a comunidade e a sociedade.

Donaire (1999) ressalta que a tecnologia de produção e de operação inclui todas as instalações e máquinas necessárias para a transformação e o processamento de matéria-prima e de produtos (semi-acabados e/ou acabados). Geralmente, a tecnologia de produção tem papel determinante, pois é a responsável direta, seja essa responsabilidade positiva ou negativa (benéfica ou agressiva ao meio ambiente), pelas emissões de resíduos variados, por parte das empresas, os quais poluem o ar, a água e o solo.

$\mathrm{Na}$ implementação de uma inovação tecnológica atuam vários atores, devido a sua complexidade, sendo o gerente de produção um desses atores. Nessa função, o profissional deve ser capaz de perceber problemas e oportunidades técnicas ou mercadológicas e trabalhar como facilitador da introdução da inovação na empresa.

O conceito de empresa ambientalmente amigável é determinado não só pelas características de seu processo produtivo, mas também pelos produtos que fabrica, obtidos de matérias-primas renováveis ou recicláveis, que não agridem o meio ambiente e que adotam as boas práticas de fabricação, diminuindo o consumo de insumos (água, energia elétrica e petróleo), ou seja, empresas engajadas na criação do desenvolvimento sustentável, conforme argumento de Donaire (1999). Esse autor recomenda, também, iniciar as ações para enquadramento de empresas ecologicamente corretas, com iniciativas que possam ter maior probabilidade de sucesso e que permitam gerar publicidade favorável, como a economia de água e energia e o uso de materiais recicláveis. 0 passo posterior, conforme Donaire (1999), é delinear ações mais polêmicas, dentre as quais destacam-se: a) atender às legislações ambientais; b) implementar ações benéficas ao meio ambiente; e c) desenvolver ações que beneficiem a comunidade e a sociedade.

Em complemento a esta posição, porém em outra perspectiva, Hart e Shrivastava (1998) destacam que, o que motivaria as empresas a se tornarem sustentáveis são três forças externas, quais 
sejam, leis mais rigorosas, ética nos negócios e correlação dos problemas ambientais com 0 desenvolvimento econômico.

De acordo com Carrieri (2000), predominam atitudes antagônicas ao desenvolvimento sustentável na maior parte das organizações. O uso e a degradação dos recursos naturais, a poluição e os resíduos ainda estão relegados ao segundo plano. A preocupação com o meio ambiente é retórica, segundo esse autor, e só será adequadamente tratada quando for valorada e trazer consigo 0 desejado lucro em função de sua implementação.

Para Ottman (1994), os produtos ecologicamente corretos estão substituindo os produtos convencionais. Os comerciantes estão atentos a mais essa oportunidade de aumentar sua participação no mercado e, como conseqüência, melhorar a imagem junto aos stakeholders.

Segundo Dinato (1998 apud NETO e LAGES, 2002, p.3), os consumidores ecologicamente conscientes são representados por indivíduos que buscam para consumo apenas produtos que causem a menor agressão ao meio ambiente. Isso pode ser aplicado a empresas que consomem produtos industriais em suas atividades. $O$ autor ressalta que os consumidores ecologicamente conscientes comportam-se conforme descrições no quadro 1.

\begin{tabular}{|l|l|}
\hline \multicolumn{1}{|c|}{ CONSUMO CONSCIENTE } & \multicolumn{1}{c|}{ DESCRIÇÃO DO COMPORTAMENTO } \\
\hline Produto & Comprar ou consumir apenas produtos que não gerem agressão ao meio ambiente. \\
\hline Reciclagem e reutilização & Utilizar apenas produtos que possam ser reciclados e/ou reutilizados. \\
\hline Segurança & Preocupação com o uso de agrotóxicos e os seus prejuízos para o meio ambiente. \\
\hline
\end{tabular}

\section{Quadro 1 - Consumidores conscientes}

Fonte: Adaptado de Neto e Lages, 2002.

Ao implementar um programa de produção mais limpa e ao divulgar as características do seu novo produto, fabricado de acordo com as especificações de novas tecnologias ecologicamente corretas, a empresa estará contribuindo para a ampliação da consciência ambiental de seus consumidores. Também auxiliará no incremento da pesquisa de novos processos de produção, além de estimular o aperfeiçoamento dos processos existentes, como os de reciclagem.

\subsection{RECICLAGEM DE RESÍDUOS SÓLIDOS}

A Agenda 21 informa que os resíduos sólidos urbanos compreendem "todos os restos domésticos e resíduos não perigosos, tais como os resíduos comerciais e institucionais, o lixo de rua e os entulhos da construção civil." (AGENDA 21, 2004). De forma mais abrangente, no capítulo 21, que versa sobre o manejo ambientalmente saudável dos resíduos sólidos, foram listadas quatro áreas prioritárias para tratar a questão da sustentabilidade: a) redução na quantidade; b) ampliação da reciclagem; c) destinação adequada dos resíduos; e d) ampliação da coleta seletiva.

A composição dos resíduos sólidos urbanos está diretamente relacionada ao grau de desenvolvimento de um país. Ao fazer uma comparação entre o Brasil e os Estados Unidos verifica-se que, em 2001, no Brasil 55\% dos resíduos gerados eram de origem orgânica e do restante somente 3\% foram classificados como resíduos plásticos, enquanto nos Estados Unidos os percentuais foram, respectivamente, de $11,2 \%$ e 10,7\% (CEMPRE, 2004a).

O grau de desenvolvimento sócio-ambiental está relacionado aos avanços tecnológicos, às leis e às normas ambientais de um país, sendo estes os fatores determinantes para o destino dos resíduos sólidos urbanos. Analisando o destino desse tipo de resíduo, comprova-se que em países desenvolvidos o percentual de reciclagem é superior ao dos países em desenvolvimento. No caso 
brasileiro, 90\% dos resíduos gerados são encaminhados para lixões, vazadouros e aterros, somente $7 \%$ têm como destino final a reciclagem e a compostagem. Em países como os Estados Unidos e a Alemanha, com maior índice de desenvolvimento econômico, o índice de reciclagem e compostagem já havia alcançado o patamar de $29 \%$ e $20 \%$, respectivamente, em 2002, conforme dados divulgados pelo CEMPRE (2004a).

Em complemento a essas informações, o Instituto Brasileiro de Geografia e Estatística - IBGE (2000) expõe que as cidades brasileiras concentram 76,8\% da população e grande parte dos problemas ambientais do país. Esse instituto divulgou no censo de 2000, que dos resíduos sólidos urbanos, no Brasil, 53\% eram destinados a lixões, 36,3\% para aterros, 5,2\% para usinas de reciclagem e 2,3\% para compostagem. Quando se analisam os dados referentes à região sul do país, onde a cidade de Florianópolis está localizada, observa-se uma variação nestes percentuais, principalmente no que diz respeito aos lixões, que passam a receber apenas 30\% dos resíduos. Uma parcela maior, ou seja, $50 \%$ é destinada a aterros, $12 \%$ para usinas de reciclagem e 4,1\% para compostagem.

O Instituto de Pesquisas Tecnológicas - IPT (1996) informa que os resíduos sólidos urbanos possuem uma grande diversidade de materiais, que poderiam ser reciclados. Dentre esses materiais, 0 plástico pode ser destacado como o mais nobre deles. Após cumprir a finalidade para a qual foi destinada, esse material pode ser utilizado em uma grande variedade de peças e utensílios, passando a ser conhecido pelas empresas de reciclagem como plástico pós-consumo.

A esse respeito, Donaire (1999) ressalta que a reciclagem começou a ser utilizada pelas próprias indústrias, para o reaproveitamento de suas perdas de produção. Quando o material passou a ser recuperado, em maior quantidade, separado do lixo, formou-se um novo mercado. Esse autor salienta que algumas empresas podem ganhar dinheiro e proteger o meio ambiente, transformando os seus pontos fracos em fortes. Como exemplo é possível citar a reciclagem de materiais, 0 reaproveitamento de resíduos e a venda de sucata proveniente dos diversos processos empresariais (produtivos, administrativos e financeiros).

A reciclagem dos materiais plásticos encontrados nos resíduos urbanos (pós-consumo) traz oportunidades econômicas, sociais e ambientais para a comunidade e para a sociedade, conforme exposto no quadro 2.

\begin{tabular}{|l|l|l|}
\hline \multicolumn{1}{|c|}{ ECONÔMICA } & \multicolumn{1}{c|}{ SOCIAL } & \multicolumn{1}{c|}{ AMBIENTAL } \\
\hline Reduzir os custos com matéria-prima. & $\begin{array}{l}\text { Gerar empregos para a população não } \\
\text { qualificada. }\end{array}$ & $\begin{array}{l}\text { Contribuir para diminuir a poluição do } \\
\text { solo, água e ar. }\end{array}$ \\
\hline $\begin{array}{l}\text { Reduzir o volume de extração de } \\
\text { petróleo. }\end{array}$ & $\begin{array}{l}\text { Melhorar a qualidade de vida da } \\
\text { população. }\end{array}$ & Prolongar a vida dos aterros. \\
$\begin{array}{l}\text { Reduzir os gastos com limpeza } \\
\text { publica. }\end{array}$ & $\begin{array}{l}\text { Contribuir para formar a consciência } \\
\text { ecológica. }\end{array}$ & $\begin{array}{l}\text { Melhorar a produção dos compostos } \\
\text { orgânicos. }\end{array}$ \\
\hline
\end{tabular}

\section{Quadro 2: Oportunidades da reciclagem de resíduos pós-consumo}

Fonte: Adaptado do CEMPRE, 2004c.

Devido à facilidade de ser moldado, o plástico tem sido utilizado na produção de uma grande variedade de artigos. 0 consumo de plástico no Brasil vem crescendo com 0 desenvolvimento econômico e acompanhando o ritmo da instalação no mercado nacional de empresas fabricantes desse material.

O programa Plastivida da ABIQUIM (2004) destaca que, em 2002, o Brasil reciclava em média $17 \%$ do plástico pós-consumo, enquanto que países como a França e os Estados Unidos reciclavam, respectivamente, $15 \%$ e 13\%. A Alemanha apresentava, na ocasião, o maior índice de reciclagem, na ordem de $60 \%$ (CEMPRE, 2002). 
Em função da dificuldade e da pulverização de informações de qualidade sobre o volume de resíduos sólidos gerados pela população, o volume de plásticos contidos nos resíduos sólidos urbanos e a quantidade de plásticos realmente reciclados no Brasil, neste trabalho, serão considerados os indicadores do CEMPRE (2004a), destacando-se os seguintes: a) a população urbana do Brasil gera 0,7 quilos per capita por dia de resíduo sólido; b) o volume de plástico no resíduo sólido urbano é de $3 \%$; e c) o volume de plástico pós-consumo reciclado é de $17 \%$.

Nesse contexto, é necessário salientar que a reciclagem secundária de resíduos plásticos pósconsumo necessita de operações adicionais, quando comparada com a reciclagem primária. Os resíduos pós-consumo são resíduos provenientes do descarte de produtos pelos consumidores. Nesse momento, a tecnologia atua como fator determinante positivo, pois permite minimizar os impactos ambientais, utilizando-se, para isso, diversas etapas: separar o plástico por tipo, lavar o resíduo, centrifugar, separar por densidade, triturar e aglutinar.

O CEMPRE (2004b) ressalta que as empresas de transformação investem em tecnologia, para diminuir a espessura das embalagens, para ganhar em produtividade e para recuperar as sobras do processo produtivo (aparas). Em contraponto e atrelado a esses fatos, o mercado busca alternativas que exigem novas funções das embalagens plásticas, como a ampliação da vida útil do produto, através da introdução de embalagens multicamadas com até cinco tipos de plásticos diferentes (coextrusão). Com isso, o mercado acaba criando barreiras para as empresas de reciclagem. Estas podem diminuir a intensidade destas barreiras e diferenciarem-se das indústrias de transformação, demonstrando para os consumidores a preocupação com a redução do desperdício de matéria-prima não renovável (no caso, petróleo) e com a melhoria da qualidade ambiental.

\section{METODOLOGIA}

Com o objetivo de verificar a existência de mercado para mangueiras corrugadas e lisas, produzidas com resíduos plásticos pós-consumo reciclados, utilizou-se de pesquisa quantitativa, com uma amostra 195 empresas, calculada de acordo com as indicações de Barbetta (2001), considerando um erro amostral de 5\%. A população total era composta por 383 empresas, distribuídas de forma representativa, levando-se em consideração o número de habitantes da zona urbana de cada município, da região da Grande Florianópolis, composta por 21 municípios. A amostra final foi constituída de 133 empresas, sendo que $32 \%$ da população consultada deixou de responder ou entregar o questionário no período solicitado.

A coleta de dados foi direcionada para a seguinte tipologia de empresas, considerada como 0 público-alvo do estudo: empresas de construção civil, lojas de materiais elétricos, lojas de materiais de construção e agropecuárias.

Utilizou-se como instrumento de coleta de dados um questionário, que solicitava informações sobre as variáveis que seguem: a) ramo de atuação da empresa; b) consumo médio mensal de mangueiras; c) identificação dos três últimos fornecedores de mangueiras; d) quantidade de sucata plástica gerada; e) destino da sucata plástica gerada; e f) intenção da empresa em comprar mangueira de material reciclado.

Neste trabalho foi utilizado o processo de amostragem não aleatória por julgamento, na escolha das empresas participantes da pesquisa, pois, de acordo com Barbetta (2001, p. 53), nesse tipo de processo o pesquisador escolhe os elementos julgados "como típicos da população que se deseja estudar". Os critérios utilizados na escolha dos participantes foram o tempo de atuação da firma no mercado, a quantidade de resíduo plástico pós-consumo gerada e a localização da mesma. Realizou-se um pré-teste, com cinco organizações, a fim de verificar a objetividade e a compreensão das perguntas, ao final do qual realizaram-se as devidas adequações. 
Pesquisa documental foi realizada para obtenção de dados sobre o setor petroquímico, sobre a região estudada e sobre os resíduos sólidos gerados. Outras informações foram obtidas através de bases de dados eletrônicas oficiais.

\section{RESULTADOS DA PESQUISA}

A pesquisa foi realizada em 133 empresas localizadas na região da Grande Florianópolis, composta pelos seguintes municípios: Águas Mornas, Alfredo Wagner, Angelina, Antônio Carlos, Biguaçu, Canelinha, Florianópolis, Anitápolis, Governador Celso Ramos, Leoberto Leal, Major Gercino, Nova Trento, Palhoça, Paulo Lopes, Rancho Queimado, Santo Amaro da Imperatriz, São Bonifácio, São João Batista, São José, São Pedro de Alcântara, e Tijucas (IBGE, 2000). Essa classificação está de acordo com a Associação dos Municípios da Grande Florianópolis - AMGF.

$\mathrm{Na}$ Tabela 1, a seguir, pode-se observar dados relativos à população total e urbana da região estudada, extraídos do censo 2000 do IBGE, e os valores projetados das quantidades de resíduos sólidos urbanos gerados, do total de plásticos contidos nestes resíduos e de plásticos encaminhados para a reciclagem. A projeção foi realizada utilizando-se os indicadores do CEMPRE (2004a).

Tabela 1 - Localidades, população e quantidades de resíduos

\begin{tabular}{l|c|c|c|c|c}
\hline \multicolumn{1}{|c|}{ LOCAL } & $\begin{array}{c}\text { POPULAÇÃO } \\
\text { TOTAL } \\
\text { (HAB.) }\end{array}$ & $\begin{array}{c}\text { POPULAÇÃO } \\
\text { URBANA } \\
\text { (HAB.) }\end{array}$ & $\begin{array}{c}\text { RESÍDUO } \\
\text { URBANO } \\
\text { (KG /DIA) }\end{array}$ & $\begin{array}{c}\text { PLÁSTICO NO } \\
\text { RESíDUO URBANO } \\
\text { (KG / MÉS) }\end{array}$ & $\begin{array}{c}\text { PLÁSTICO } \\
\text { RECICLADO } \\
\text { (KG / MÊS) }\end{array}$ \\
\hline Grande Florianópolis & 873.970 & 735.117 & 514.582 & 463.123 & 78.731 \\
\hline Santa Catarina & 5.607 .233 & 4.217 .763 & 2.952 .434 & 2.657 .191 & 451.720 \\
\hline Brasil & 170.000 .000 & 137.925 .238 & 96.547 .666 & 86.892 .899 & 14.771 .792 \\
\hline
\end{tabular}

Fonte: Adaptada do IBGE, 2000 e CEMPRE, 2004a

Através da Tabela 1 é possível constatar que em torno de 384 toneladas de plástico pósconsumo poderiam ser encaminhadas para empresas de reciclagem, na região estudada. Considerando esses valores como referencial, expressa-se o potencial que o Brasil possui para a implantação de empresas de reciclagem de plástico. Existe, portanto, um amplo campo para implementação de processo de produção mais limpa na Grande Florianópolis.

As empresas consultadas pertenciam ao ramo de construção civil e agropecuária, que são os principais usuários desse tipo de produto - mangueiras plásticas. Além disso, foram pesquisadas as empresas varejistas que comercializam o produto para pequenas empresas e consumidores finais, conforme apresentado na Tabela 2.

Tabela 2: Característica da amostra

\begin{tabular}{l|c|c}
\hline \multicolumn{1}{c|}{ TIPOLOGIA } & QUANTIDADE & $\%$ \\
\hline Construtoras & 29 & 22 \\
\hline Agropecuárias & 8 & 6 \\
\hline Lojas de Material de Construção & 76 & 57 \\
\hline Lojas de Material Elétrico & 20 & 15 \\
\hline Total & 133 & 100 \\
\hline
\end{tabular}

Fonte: Elaborado pelos autores 
A pesquisa também revelou que $74 \%$ das empresas pesquisadas consomem em média, mensalmente, até 20 rolos de mangueira de 100 metros cada, conforme apresentado na Tabela 3.

Tabela 3 - Consumo médio mensal de mangueiras

\begin{tabular}{l|c|c}
\hline $\begin{array}{c}\text { CONSUMO MÉDIO MENSAL } \\
\text { (ROLOS DE 100 METROS) }\end{array}$ & NÚMERO DE EMPRESAS & $\%$ \\
\hline 01 a 10 & 33 & 25 \\
\hline 11 a 20 & 65 & 49 \\
\hline 21 a 30 & 23 & 17 \\
\hline Mais de 30 & 12 & $\mathbf{1 0 0}$ \\
\hline Total & $\mathbf{1 3 3}$ & \\
\hline
\end{tabular}

Fonte: Dados da pesquisa

As vendas das mangueiras para as empresas pesquisadas estavam concentradas em apenas cinco fornecedores, fabricantes tradicionais e de longa data de atuação no mercado catarinense, sendo que $74 \%$ das operações eram realizadas por apenas três deles, conforme pode ser visualizado no Gráfico 1.

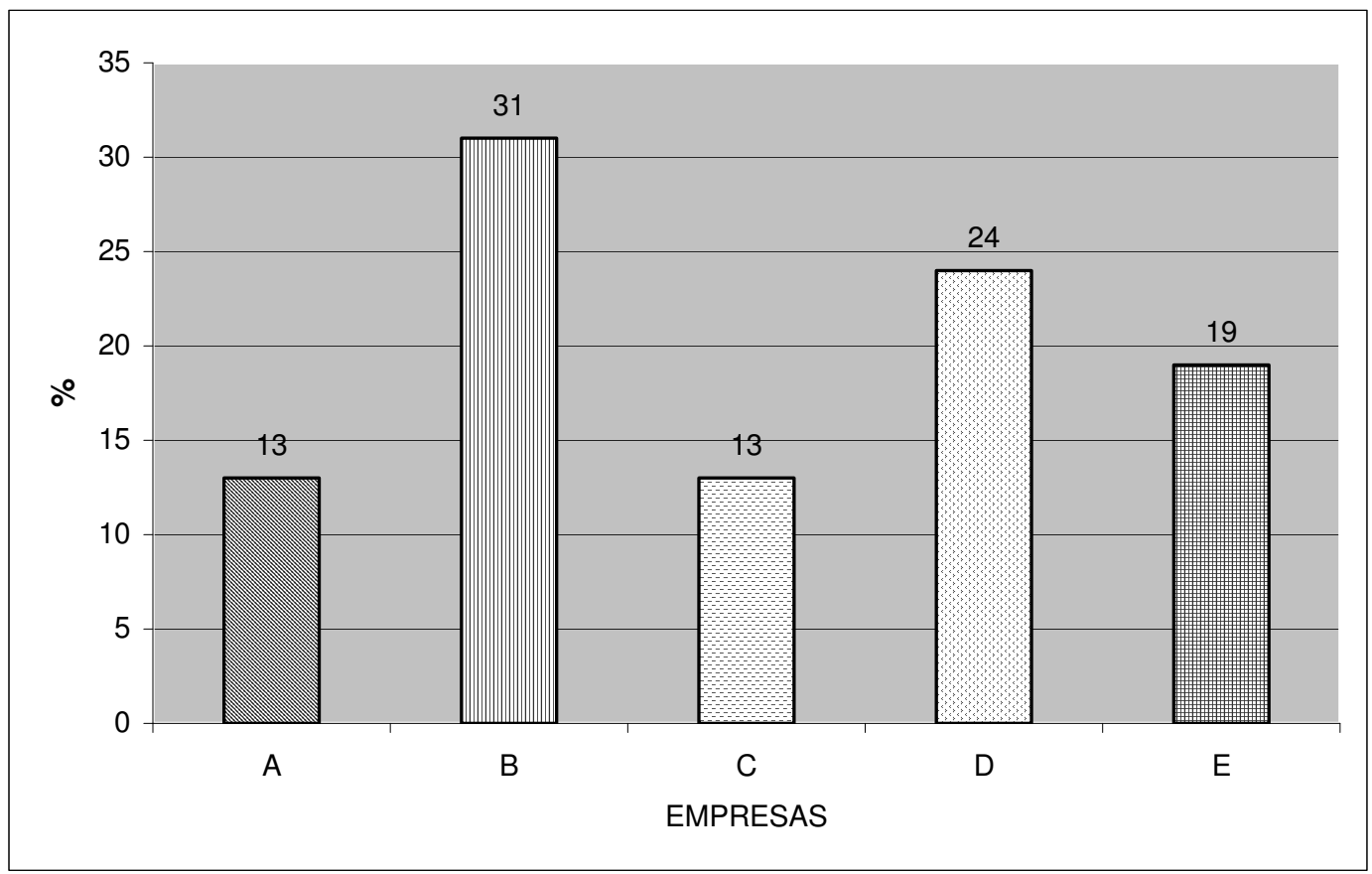

\section{Gráfico 1 - Empresas fabricantes de mangueiras}

Fonte: Dados da pesquisa

Quanto ao volume de sucata plástica gerada na região, conforme Gráfico 2, observou-se que $68 \%$ das empresas geravam até $500 \mathrm{~kg}$ por mês de sucata plástica, cada uma. Quando questionados sobre a destinação desta sucata, $74 \%$ dos respondentes mencionaram que não revendiam esse 
subproduto, optando pela doação do mesmo como destino final. Porém, não informaram para quem eram feitas as doações. As empresas cujo volume de sucata gerada era muito pequeno informaram que a Prefeitura Municipal, através da coleta de lixo urbano, recolhia esses resíduos. Cabe salientar que, na maior parte dos municípios da região da Grande Florianópolis, não há coleta seletiva de lixo implantada (COMCAP, 2004).

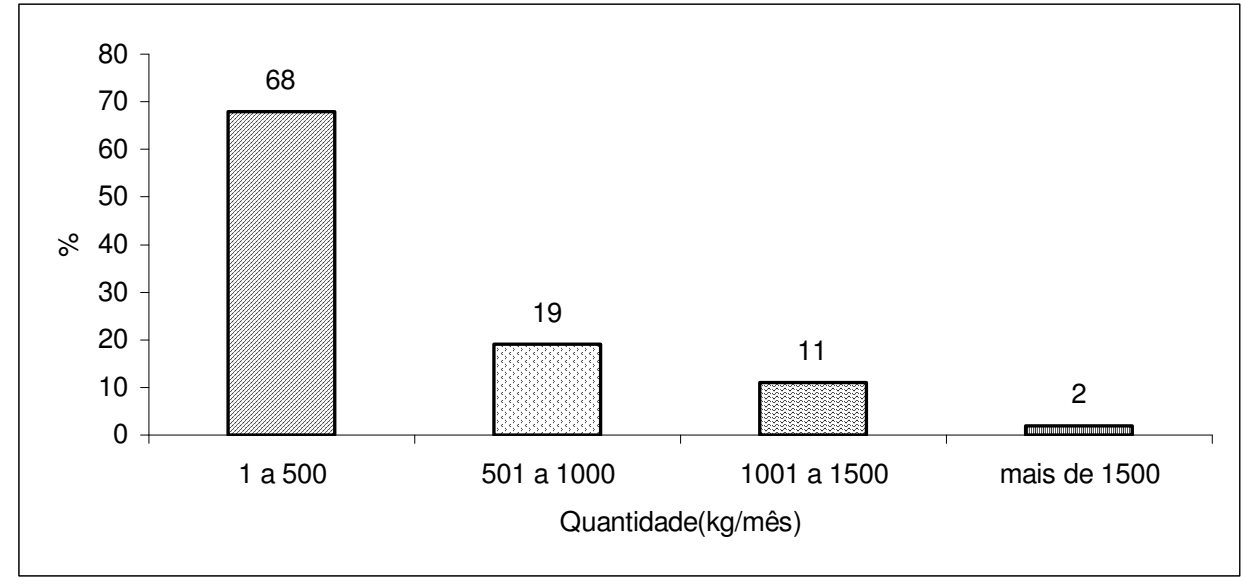

\section{Gráfico 2 - Volume de sucata gerada}

Fonte: Dados da pesquisa

Quando solicitados a informar se estavam dispostos a comprar mangueiras plásticas fabricadas com matéria-prima não reciclada, $69 \%$ das empresas responderam de forma afirmativa. Entretanto, dentre essas empresas, apenas $58 \%$ responderam negativamente ao se perguntar sobre a probabilidade de adquirir o mesmo produto fabricado com resíduo plástico reciclado. Essa informação está em desacordo com os dados das empresas fabricantes de mangueiras no estado de Santa Catarina, pois, segundo os mesmos, mais de $80 \%$ das mangueiras (lisa e corrugada) de plástico utilizadas são provenientes da reciclagem de resíduos plásticos pós-consumo. Isso pressupõe que as empresas não estão informadas sobre a origem da matéria-prima do material consumido. Além disso, é razoável supor que, embora as empresas de reciclagem estejam contribuindo para a sustentabilidade ambiental, esse fato não está sendo devidamente divulgado entre os usuários dos produtos.

Esses resultados revelam a necessidade de melhor divulgação dessa inovação tecnológica, a fim de que a adoção do produto reciclado seja realmente efetivada pela população. Conforme Kotler (2000), para que isso ocorra é necessário, num primeiro momento, a implementação de uma campanha de conscientização dos benefícios do novo produto, para que o consumidor seja levado a seguir as demais etapas do processo de adoção da nova tecnologia.

\section{CONSIDERAÇÕES FINAIS}

O mercado de resíduos plásticos pós-consumo da Grande Florianópolis apresenta um grande potencial de crescimento e poderá, se devidamente tratado, representar uma importante fonte de renda para a comunidade. Atualmente, a procura por resíduos plásticos pós-consumo de boa qualidade é muito grande. No entanto, observou-se que a compra desses resíduos está concentrada na mão de poucos intermediários, o que vem inflacionando o custo dessa matéria-prima e dificultando o ingresso de novas empresas de reciclagem no mercado. 
Com o crescimento da consciência ecológica, por parte da população, e uma maior cobrança do poder público, quanto ao destino ecologicamente correto dos resíduos pós-consumo, a implantação e ampliação da coleta seletiva, na região da Grande Florianópolis, tornam-se inevitáveis, contribuindo dessa forma, com o fornecimento de resíduos mais limpos e, conseqüentemente, mais fáceis de serem reciclados.

Como existe uma grande quantidade de resíduo plástico pós-consumo direcionada para lixões e aterros surge a oportunidade para a implantação de outras empresas de reciclagem na região, as quais ampliarão o uso de tecnologias de produção mais limpa, contribuindo para a sustentabilidade econômica e ambiental da região.

Tendo em vista que os consumidores de mangueiras plásticas desconhecem a origem das matérias-primas utilizadas em sua fabricação, recomenda-se que as empresas fabricantes deste material se responsabilizem pela implantação de um programa de comunicação integrada, informando os benefícios econômicos e ambientais do novo produto e do processo de fabricação para os seus consumidores potenciais, sensibilizando-os sobre as vantagens do uso de produtos fabricados com resíduos plásticos pós-consumo. Dessa forma, estarão também contribuindo para a educação desses indivíduos.

\section{REFERÊNCIAS}

ABIQUIM - Associação Brasileira da Indústria Química. Disponível em: <http://www.abiquim.org.br/conteudo.asp?prince=ain>. Acesso em: 27 set. 2004.

AGENDA 21. Disponível em: <http://www.mma.gov.br/?id_estrutura>. Acesso em: 15 ago. 2004.

BARBETTA, P. A. Estatística aplicada às ciências sociais. 3. ed. Florianópolis: UFSC, 2001.

BARBIERI, J. C. A. Contribuição da Área Produtiva no Processo de Inovações Tecnológicas. Revista de Administração de Empresas, 37, (jan/mar), p. 66-77, 1997.

BETZ, F. Managing Tecnology. New Jersey: Prentice-Hall, 1987.

CARRIERI, A. P. O meio ambiente: Discurso ou retórica? IN: ENCONTRO ANUAL DA ANPAD, Anais... Florianópolis: ANPAD, 2000.

CEMPRE - Compromisso Empresarial para Reciclagem. 2002. Disponível em: <http://www.cempre.org.br/2002_inter.php>. Acesso em: 22 out. 2004.

CEMPRE - Compromisso Empresarial para Reciclagem. 2004. Disponível em: <http://www.cempre.org.br/2004.0506_inter.php>. Acesso em: 03 jul. 2004a.

CEMPRE - Compromisso Empresarial para Reciclagem. 2004. Disponível em: <http://www.cempre.org.br/2004.0102_inter.php>. Acesso em: 02 mar. 2004b.

CEMPRE - Compromisso Empresarial para Reciclagem. 2004. Disponível em: <http://www.cempre.org.br/2004.0304_inter.php>. Acesso em: 05 mai. 2004c.

COMCAP - Companhia de Melhoramento da Capital. Disponível em: <http://www.comcap.gov.br>. Acesso em: 19 jun. 2004.

DONAIRE, D. Gestão ambiental na empresa. 2 ed. São Paulo: Atlas, 1999. 
HART, S. SHRIVASTAVA, P. Por uma gestão ambiental total: as empresas devem usar a filosofia dos programas de gestão da qualidade total e buscar a meta 'zero poluição'. HSM Management, n.6, p. 9296, jan./fev 1998.

IBGE - Instituto Brasileiro de Geografia e Estatística. Censo 2000. Disponível em: <http://www.ibge.gov.br/home/estatistica/populaçao/censo2000>. Acesso em: 10 mai. 2004.

IPT. Lixo Municipal: Manual de gerenciamento integrado. São Paulo: Páginas e Letras, 1996.

KOTLER, P. Administração de Marketing: a edição do novo milênio. São Paulo: Prentice-Hall, 2000.

NETO, A.V. LAGES, N. S. Mensurando a consciência ecológica do consumidor: um estudo realizado na cidade de Porto Alegre. IN: ENCONTRO ANUAL DA ANPAD. Anais... Salvador: ANPAD, 2002.

OTTMAN, J. A. Marketing verde: desafios e oportunidades para o nova era do marketing. São Paulo: Makron Books, 1994.

ROGERS, E. M. Diffusion of innovation. 3.ed. New York: Free Press, 1983.

SINDUSCOM. Sindicato das Indústrias da Construção Civil. Disponível em: http://www.sinduscom.com.br. Acesso em: 03 fev.2005.

STONER, J. A F., FREEMAN, R. E. Administração. 5. ed. Rio de Janeiro: Livros Técnicos e Científicos, 1982.

UNIDO. Cleaner Production. Disponível em: < http://www.unido.org/doc/4460> Acesso em: 08 set.2004.

\section{INNOVATION TECHNOLOGY AND ACCEPTANCE PROCESS OF PRODUCTS MANUFACTURED FROM POST- CONSUMPTION PLASTIC RESIDUE}

The reuse of products in the recycling process results in a much cleaner production, considered innovation technology. With the aim of ascertain market viability for hoses manufactured from recycled post-consumption plastic residue, a research was carried out in 133 companies of the City of Florianopolis - State of Santa Catarina, identifying amount consumed and willingness to acquire this new product. Findings show that a substantial amount of post-consumption plastic residue, generated in the region, could be utilized for the production of hoses, and that, users of this product needed to be informed about the benefits of using a product manufactured from recycled raw material.

Key words: Cleaner production.linnovation technology. Acceptance of new products. Post-consumption plastic residue.

Data de submissão: outubro de 2006 Data de aceite: fevereiro de 2007 